\title{
The Gliotransmitter D-Serine Promotes Synapse Maturation and Axonal Stabilization In Vivo
}

\author{
Marion R. Van Horn, ${ }^{1}$ Arielle Strasser, ${ }^{1}$ Lois S. Miraucourt, ${ }^{1}{ }^{\circ}$ Loredano Pollegioni, ${ }^{2,3}$ and ${ }^{\circ}$ Edward S. Ruthazer ${ }^{1}$ \\ ${ }^{1}$ Department of Neurology and Neurosurgery, Montreal Neurological Institute, McGill University, Montreal, Quebec H3A 2B4, Canada, ${ }^{2}$ Dipartimento di \\ Biotecnologie e Scienze della Vita, Università degli studi dell'Insubria, 21100 Varese, Italy, and ${ }^{3}$ The Protein Factory, Centro Interuniversitario di \\ Biotecnologie Proteiche, Politecnico di Milano and Università degli Studi dell'Insubria, 20131 Milano, Italy
}

The NMDAR is thought to play a key role in the refinement of connectivity in developing neural circuits. Pharmacological blockade or genetic loss-of-function manipulations that prevent NMDAR function during development result in the disorganization of topographic axonal projections. However, because NMDARs contribute to overall glutamatergic neurotransmission, such loss-of-function experiments fail to adequately distinguish between the roles played by NMDARs and neural activity in general. The gliotransmitter D-serine is a coagonist of the NMDAR that is required for NMDAR channel opening, but which cannot mediate neurotransmission on its own. Here we demonstrate that acute administration of D-serine has no immediate effect on glutamate release or AMPA-mediated neurotransmission. We show that endogenous D-serine is normally present below saturating levels in the developing visual system of the Xenopus tadpole. Using an amperometric enzymatic biosensor, we demonstrate that glutamatergic activation elevates ambient endogenous D-serine levels in the optic tectum. Chronically elevating levels of D-serine promoted synaptic maturation and resulted in the hyperstabilization of developing axon branches in the tadpole visual system. Conversely, treatment with an enzyme that degrades endogenous D-serine resulted in impaired synaptic maturation. Despite the reduction in axon arbor complexity seen in D-serine-treated animals, tectal neuron visual receptive fields were expanded, suggesting a failure to prune divergent retinal inputs. Together, these findings positively implicate NMDAR-mediated neurotransmission in developmental synapse maturation and the stabilization of axonal inputs and reveal a potential role for $\mathrm{D}$-serine as an endogenous modulator of circuit refinement.

Key words: D-serine; gliotransmission; plasticity; retinotectal; visual system; Xenopus laevis

Significance Statement

Activation of NMDARs is critical for the activity-dependent development and maintenance of highly organized topographic maps. D-Serine, a coagonist of the NMDAR, plays a significant role in modulating NMDAR-mediated synaptic transmission and plasticity in many brain areas. However, it remains unknown whether D-serine participates in the establishment of precise neuronal connections during development. Using an in vivo model, we show that glutamate receptor activation can evoke endogenous D-serine release, which promotes glutamatergic synapse maturation and stabilizes axonal structural and functional inputs. These results reveal a pivotal modulatory role for D-serine in neurodevelopment.

\section{Introduction}

Making appropriate connections between neurons is essential for establishing functional neural networks. Molecular guidance

Received Oct. 11, 2016; revised April 29, 2017; accepted May 18, 2017.

Author contributions: M.R.V.H., L.S.M., L.P., and E.S.R. designed research; M.R.V.H., A.S., and L.S.M. performed research; L.P. contributed unpublished reagents/analytic tools; M.R.V.H., A.S., and E.S.R. analyzed data; M.R.V.H., L.S.M., L.P., and E.S.R. wrote the paper.

This work was supported by Natural Sciences and Engineering Research Council Banting Postdoctoral Fellowship to M.R.V.H. and Canadian Institutes of Health Research Operating Grant to E.S.R. E.S.R. is a tier 2 Canada Research Chair and Fonds de la Recherche en Santé du Québec chaire de recherche. We thank Zahraa Chorghay for help with editing the manuscript.

The authors declare no competing financial interests.

Correspondence should be addressed to Dr. Edward S. Ruthazer, Department of Neurology and Neurosurgery, Montreal Neurological Institute, McGill University, Montreal, Quebec H3A 2B4, Canada. E-mail: edward.ruthazer@mcgill.ca. cues direct axons to appropriate target locations, whereas patterned neuronal activity directs the refinement of precise circuit connectivity (Assali et al., 2014; Kutsarova et al., 2017). Recent work in the developing visual system has underscored the ability of correlated patterns of neural activity to stabilize dynamically remodeling axon arbors. Axonal branches fail to stabilize if NMDARs are blocked during coactivation of inputs (Munz et al., 2014). Moreover, blockade of NMDARs can lead to an increase in axonal branch dynamics in the developing visual system (Rajan et al., 1999) and results in a severe disorganization of topographic 
axonal projections (Cline et al., 1987; Simon et al., 1992). Despite the prominent impact on neuronal morphogenesis that has been observed in response to NMDAR knock-out or pharmacological blockade, such loss-of-function experiments suffer from the confound that NMDARs also contribute significantly to normal patterned excitatory transmission (Feldman et al., 1996; Ruthazer et al., 2003).

NMDARs are unique because their activation requires both the binding of glutamate at the GluN2 subunit as well as binding of a coagonist at the so-called "glycine site" on the GluN1 subunit (Wolosker, 2007). Although changes in coagonist levels are likely important for regulating NMDAR activation, whether they play an active role in regulating the development of neuronal circuits is not known. The transmitter glycine has long been identified as a coagonist at the NMDAR (Johnson and Ascher, 1987; Danysz and Parsons, 1998). The possibility that neuronal NMDAR currents might be modulated by glia-derived factors gained favor following the discovery that another NMDAR coagonist, D-serine, which is abundant in vertebrate brain with a general distribution that resembles that of NMDARs (Hashimoto et al., 1993), is found principally within glial cells (Schell et al., 1995).

It is now generally accepted that D-serine is a gliotransmitter which, along with glycine, plays a significant role in modulating NMDAR-mediated synaptic transmission and plasticity in many brain areas (Van Horn et al., 2013; Mothet et al., 2015). Whether dynamic modulation of NMDARs by glycine and D-serine contributes to regulating the establishment of precise neuronal connections during development remains an open question. Because glycine also functions as an inhibitory neurotransmitter, we have focused on manipulation of D-serine, as it offers a cleaner approach to studying the effects of NMDAR coagonist modulation in circuit development. Here, using the retinotectal projection in the developing Xenopus tadpole as a model, we demonstrate that D-serine release in the brain is modulated by glutamatergic transmission and that D-serine levels influence retinotectal circuit development by promoting the functional and structural stabilization of retinal axon inputs within the optic tectum.

\section{Materials and Methods \\ Husbandry}

All procedures were approved by the Animal Care Committee of the Montreal Neurological Institute at McGill University in accordance with Canadian Council on Animal Care guidelines. Albino Xenopus laevis frogs (RRID:NXR_0.0082) were injected with human chorionic gonadotropin (Sigma-Aldrich) and pregnant mare serum gonadotropin (Sigma-Aldrich) to induce mating. Eggs were collected and raised in $0.1 \times$ Modified Barth's Solution with HEPES (MBSH; $88 \mathrm{~mm} \mathrm{NaCl}, 1 \mathrm{~mm} \mathrm{KCl,} 2.4 \mathrm{~mm} \mathrm{NaHCO}$, $0.82 \mathrm{~mm} \mathrm{MgSO}_{4} \times 7 \mathrm{H}_{2} \mathrm{O}, 0.33 \mathrm{~mm} \mathrm{Ca}\left(\mathrm{NO}_{3}\right)_{2}, \times 4 \mathrm{H}_{2} \mathrm{O}, 0.41 \mathrm{~mm} \mathrm{CaCl}_{2}, 10$ mM HEPES, pH 7.4). Tadpoles of both sexes were used for all studies.

\section{Immunohistochemistry}

Stage 48 tadpoles were electroporated across the tectal ventricle to express membrane-targeting farnesylated EGFP in radial glia. At least $24 \mathrm{~h}$ after electroporation, animals were anesthetized in tricaine methanesulfonate (MS222, $0.2 \% \mathrm{w} / \mathrm{v}$ ) and fixed by immersion in $4 \%$ PFA with $0.5 \%$ glutaraldehyde in $0.1 \mathrm{M}$ phosphate buffer and then cryoprotected overnight at $4^{\circ} \mathrm{C}$ in $30 \%$ sucrose (Sigma). Cryostat sections were cut at $20 \mu \mathrm{m}$ thickness after embedding in Tissue-Tek OCT Compound (PELCO International). Sections were permeabilized ( $0.3 \%$ Triton X-100, Sigma) and incubated in blocking solution containing 5\% normal goat serum (Invitrogen), 10\% BSA, and $0.3 \%$ Triton X-100 for $1 \mathrm{~h}$, followed by application of primary antibody for $2 \mathrm{~h}$. D-Serine was labeled using a rabbit polyclonal antibody $(1: 1000$, ab6472, Abcam). Secondary antibodies conjugated to AlexaFluor-555 (1:400, Invitrogen) were applied for $1 \mathrm{~h}$. Slides were then rinsed in phosphate buffer and coverslipped in
Vectashield mounting medium (Vector Laboratories). Sections were imaged on a Zeiss LSM 510 inverted confocal microscope.

\section{Enzymes and drugs}

Recombinant wild-type Rhodotorula gracilis D-amino acid oxidase (RgDAAO) was overexpressed in Escherichia coli cells and purified as reported previously (Molla et al., 1998). This enzyme shows a specific activity of $75 \mathrm{U} / \mathrm{mg}$ protein on $\mathrm{D}$-serine and a higher specificity for $\mathrm{D}$-serine than for glycine. The apparent kinetic efficiencies for these two compounds are 3.0 and $0.058 \mathrm{~mm}^{-1} \mathrm{~s}^{-1}$ ) (i.e., RgDAAO is 1740 -fold more efficient on D-serine than on glycine). Inactivation of $\mathrm{RgDAAO}$ was produced by heating the enzyme to $100^{\circ} \mathrm{C}$ for $10 \mathrm{~min}$.

Drugs used were picrotoxin (PTX, $100 \mu \mathrm{M})$, TTX (1 $\mu \mathrm{M})$, NBQX salt $(20 \mu \mathrm{M}), \mathrm{L}-689,560(20 \mu \mathrm{M})$, D-serine $(10-500 \mu \mathrm{M})$, AMPA $(100 \mu \mathrm{M})$, cyclothiazide $(50 \mu \mathrm{M})$, and MK-801 $(10 \mu \mathrm{M})$. For the electrophysiological and the enzymatic biosensor experiments, drugs were all bath-applied at a constant perfusion rate. For rearing experiments, the drugs were added directly to the animals' rearing solution. All drugs were purchased from Tocris Bioscience.

\section{Electrophysiology}

Tectal whole-cell patch-clamp recordings were made in the isolated intact brain from Stage 46-47 albino Xenopus laevis tadpoles. Briefly, tadpoles were first anesthetized with MS222 $(0.02 \%$ in $0.1 \% \mathrm{MBSH})$ and then placed in cold HEPES-buffered extracellular saline, which consisted of the following (in mM): $115 \mathrm{NaCl}, 4 \mathrm{KCl}, 3 \mathrm{CaCl}_{2}, 3 \mathrm{MgCl}_{2}, 5 \mathrm{HEPES}$, and 10 glucose, $\mathrm{pH} 7.2$ (osmolarity: $\sim 250 \mathrm{mOsm}$ ). An incision was made along the dorsal midline of the optic tectum to expose the ventricular surface, and the brain was dissected out and pinned to a block of Sylgard in a recording chamber with continuous perfusion of room temperature extracellular saline. To gain access to tectal neurons, part of the ventricular membrane was carefully removed using a broken micropipette. Individual tectal neurons were visualized using an Olympus BX51 upright microscope with a $60 \times(0.9 \mathrm{NA})$ water-immersion objective and a CCD camera (Sony XC-75).

Voltage-clamp recordings from tectal neurons were obtained using patch recording pipettes $(6-10 \mathrm{M} \Omega$, Sutter Instruments) containing the following (in mM): $90 \mathrm{CsMeSO}_{4}, 20 \mathrm{HEPES}, 20$ tetraethylammonium, 10 EGTA, $5 \mathrm{MgCl}_{2}$, 2 ATP, 0.3 GTP, pH 7.20 (osmolarity: $250 \mathrm{mOsm}$ ). Miniature AMPA-mediated EPSCs (mEPSCs) were recorded in the presence of the GABAA antagonist, PTX $(100 \mu \mathrm{M})$, and TTX $(1 \mu \mathrm{M})$ at a holding potential of $-70 \mathrm{mV}$.

Retinal ganglion cell (RGC) axons were stimulated using a $25 \mu \mathrm{m}$ cluster stimulating electrode (FHC) placed on the optic chiasm (100 $\mu \mathrm{s}$ pulses). Electrical stimuli were generated using an ISO-flex stimulus isolation unit (AMPI). NMDAR-mediated mEPSCs were isolated by clamping the cell at $-70 \mathrm{mV}$ in a $\mathrm{Mg}^{2+}$ free external, which contained NBQX to block AMPARs.

\section{Receptive field mapping}

Stage 46-47 tadpoles were paralyzed by intraperitoneal injection of D-tubocurarine $(2.5 \mathrm{~mm})$ and then transferred to a recording chamber for in vivo whole-cell recordings. The tadpole was held in place in a customshaped Sylgard chamber using insect pins and then was covered with external recording solution. A small incision was made along the dorsal midline of the optic tectum to expose the contralateral ventricular surface and a broken patch pipette was used to carefully expose tectal neurons. A multicore optical image fiber (FIGH-30-650S, Myriad Fiber) coupled to a projector (Optoma) was placed in front of the contralateral eye, and visual stimuli was generated using custom ImageJ macros. White squares on a black background arranged on a $7 \times 7$ grid were presented in a random fashion for $1 \mathrm{~s}$ every $5 \mathrm{~s}$, until the entire receptive field was mapped. All stimuli were presented at least twice.

Light-evoked compound synaptic currents (CSCs) were recorded using patch pipettes $(6-10 \mathrm{M} \Omega)$ containing the following (in $\mathrm{mM}$ ): 100 K-gluconate, $8 \mathrm{KCl}, 5 \mathrm{NaCl}, 1.5 \mathrm{MgCl}_{2}, 20 \mathrm{HEPES}, 10 \mathrm{EGTA}, 2 \mathrm{ATP}, 0.3$ GTP, pH 7.3 (Osm 250). Cells were voltage-clamped at $-70 \mathrm{mV}$.

The synaptic response for each subfield of the $7 \times 7$ grid was calculated by integrating the current over a period of $400 \mathrm{~ms}$ after illumination (ON response) and also after the extinction (OFF response) of the stimulus. 
Responses were averaged for every subfield. Receptive fields were plotted as image maps, with the brightest square $(100 \%)$ corresponding to the subfield with the largest response. Receptive field size was calculated by counting the number of stimulus locations whose average response was $>3$ SDs above the baseline noise.

\section{Electrophysiological data analysis}

Electrophysiological recordings were made using an Axopatch 200B amplifier (Molecular Devices), and signals were digitized (Digidata 1220) and sampled at $10 \mathrm{kHz}$, filtered at $2 \mathrm{kHz}$. pClamp 8 software was used for offline analysis. mEPSCs were analyzed using the MiniAnalysis software (Synaptosoft).

AMPA/NMDA ratios were calculated by comparing evoked synaptic responses at $-70 \mathrm{mV}$ to measure AMPAR-mediated EPSCs to evoked responses measured at $40 \mathrm{mV}$ to measure the NMDAR-mediated EPSCs. The NMDA component was measured $50 \mathrm{~ms}$ after stimulation onset. In paired-pulse experiments, interstimulus intervals (ISIs) of 50, 100, and $150 \mathrm{~ms}$ were used, unless otherwise specified. Paired-pulse ratio (PPR) was calculated as the peak amplitude of the second EPSC (EPSC2) divided by the peak amplitude of the first EPSC (EPSC1).

\section{Amperometric enzymatic biosensor}

Custom-designed enzymatic biosensors were purchased from Sarissa Biomedical. Detection of D-serine using the biosensor relies on the stoichiometric production of hydrogen peroxide during the enzymatic oxidation of D-serine that diffuses through the perm-selective layer and is oxidized at the biased platinum surface, which is polarized to $500 \mathrm{mV}$.

Before and after each recording session, calibrations were done with $0-20 \mu \mathrm{M}$ D-serine. Detection of D-serine release was made from the brains of Stage 48 tadpoles. Following anesthesia with MS222 $(0.02 \%$ in $0.1 \% \mathrm{MBSH})$, brains were dissected out in cold HEPES-buffered extracellular saline, which contained PTX $(100 \mu \mathrm{M})$ and TTX $(1 \mu \mathrm{M})$. To expose the ventricular and pial surfaces of the optic tectum, brains were fileted down the midline and pinned to a piece of Sylgard, which was submerged in a recording chamber perfused with fresh, room temperature, extracellular saline.

The biosensor was inserted into the optic tectum so that the enzymecoated surface was in complete contact with tissue. Close attention was paid to ensure that the angle and orientation of the biosensor were consistent between experiments. After insertion into the tissue, the biosensor was allowed to stabilize for at least $30 \mathrm{~min}$, until a steady-state baseline was achieved. Drugs were washed into the recording chamber and then washed off after $10 \mathrm{~min}$.

To control for nonspecific artifacts and noise, the same procedure described above was performed using null biosensors (Sarissa Biomedical), which are identical to the enzymatic biosensors but without an active DAAO layer. The average current generated from the null electrode was subtracted from the current measured from D-serine sensor after wash-on of AMPA with cyclothiazide to get a more accurate estimate of the amount of D-serine released.

Electrochemical measurements were performed using an Axopatch 200B amplifier (Molecular Devices) and digitized at $2 \mathrm{kHz}$. Traces were recorded using pClamp 10 software. Offline analysis was done using Clampfit software (Molecular Devices), and traces for the figures were low pass filtered with a cutoff frequency of $5 \mathrm{~Hz}$. For each experiment, an average baseline measure was taken as the average current $1 \mathrm{~min}$ before the start of the drug wash-on and then average currents were measured over 1 min intervals throughout the duration of the experiments.

\section{Electroporation}

As described in detail previously (Ruthazer et al., 2013), plasmid encoding farnesylated EGFP was electroporated into the eye of Stage 43-45 tadpoles. Tadpoles were anesthetized in MS222 (0.02\% in 0.1\% MBSH) and placed on a Kimwipe under a dissecting microscope. A small volume of EGFP plasmid $(1.5 \mu \mathrm{g} / \mu \mathrm{l})$, with a small amount of fast green dye, was injected into the vitreous humor between the eye and the lens. A pair of custom-made platinum plate electrodes, connected to an electrical stimulator (SD 9, Grass Instruments), was placed around the eye, and six pulses (30 V intensity, $1.6 \mathrm{~ms}$ duration) were delivered to electrodes.
A $3 \mu \mathrm{F}$ capacitor was connected in parallel to the electrodes to produce an exponential waveform.

\section{In vivo imaging}

In vivo two-photon imaging was done using a confocal microscope custom-built for multiphoton imaging with a $60 \times$ water-immersion objective (1.1 NA). Excitation light was produced by a Maitai-BB Ti:Sapphire femtosecond pulsed IR laser (Spectra Physics), and $z$-series optical sections were collected at $1 \mu \mathrm{m}$ intervals using Fluoview software (version 5.0).

Daily imaging. At $24-48 \mathrm{~h}$ after electroporation, animals were screened for 1-2 well-separated, simple EGFP-expressing axons growing into the optic tectum. Only simple axons with $<20$ branches on the first day of imaging were included for this study to observe the period of peak remodeling. Animals were anesthetized in MS222 (0.02\% in $0.1 \%$ $\mathrm{MBSH}$ ) and placed in a custom-made Sylgard chamber that was fit to the tadpole's body. Two-photon imaging acquisition took $\sim 10 \mathrm{~min}$, after which the animals were returned to an isolated well that contained control MBSH, MBSH with $100 \mu \mathrm{M}$ D-serine, MBSH with $10 \mu \mathrm{M}$ MK-801, or MBSH with $10 \mu \mathrm{M}$ MK-801 and $100 \mu \mathrm{M}$ D-serine. Images were collected every day for $4 \mathrm{~d}$, and MBSH solutions were changed daily.

Short interval imaging. At $24 \mathrm{~h}$ after animals were electroporated with EGFP, animals were screened for single axons growing in the optic tectum. Animals were placed in isolated wells containing either control MBSH or MBSH with $100 \mu \mathrm{M}$ D-serine. Two-photon images of single isolated axons were acquired $48-72 \mathrm{~h}$ later. Before each imaging session, animals were anesthetized in MS222 (0.02\% in 0.1\% MBSH) for $5 \mathrm{~min}$. Optical section $z$-series were collected at $1 \mu \mathrm{m}$ intervals every $10 \mathrm{~min}$ for $1 \mathrm{~h}$.

\section{Image analysis}

For daily imaging, axons were first deconvolved using AutoQuant software and then reconstructed in $3 \mathrm{D}$ using the autodepth feature in Imaris (Bitplane). For short interval imaging, images were manually reconstructed in 3D for dynamic morphometric analysis using Dynamo Software written in MATLAB (The MathWorks; generously provided by Dr. Kurt Haas, University of British Columbia) (Hossain et al., 2012).

\section{Statistical analysis}

All data are expressed as mean $\pm \mathrm{SEM}$, and $N$ values refer to the number of cells. Electrophysiology data were tested for normality by a D'AgostinoPearson test, and statistical comparisons between groups were performed using two-tailed Student's $t$ tests or Mann-Whitney tests. A KolmogorovSmirnoff test was used to compare cumulative probability distributions. Morphometric time-lapse analyses were performed using a repeatedmeasures two-way ANOVA followed by a Holm-Sidak post hoc test. GraphPad Prism software was used to perform analyses.

\section{Results}

\section{D-Serine is enriched in the neuropil and radial glia cells of the developing Xenopus optic tectum}

D-Serine is an endogenous coagonist for NMDARs in many brain areas. We examined the distribution of $\mathrm{D}$-serine in the optic tectum of Xenopus laevis tadpoles that had been electroporated to drive mosaic expression of membrane-targeting farnesylated EGFP in radial glial cells (Fig. $1 A, B$ ). Radial glial cells in Xenopus have been found to perform many of the functions attributed in the mammalian brain to astrocytes, a cell type that is not found in the tadpole brain (Tremblay et al., 2009; Sild et al., 2016). D-Serine immunohistochemistry revealed that it is present throughout the optic tectum and is enriched in the neuropil and radial glial cell bodies, consistent with observations in other species that implicate glial cells as a significant source of D-serine release (Fig. 1B).

\section{D-Serine is an endogenous ligand of NMDARs in the developing optic tectum}

To examine the contribution of coagonist binding to retinotectal synaptic activity, NMDAR-mediated EPSCs in tectal neurons 

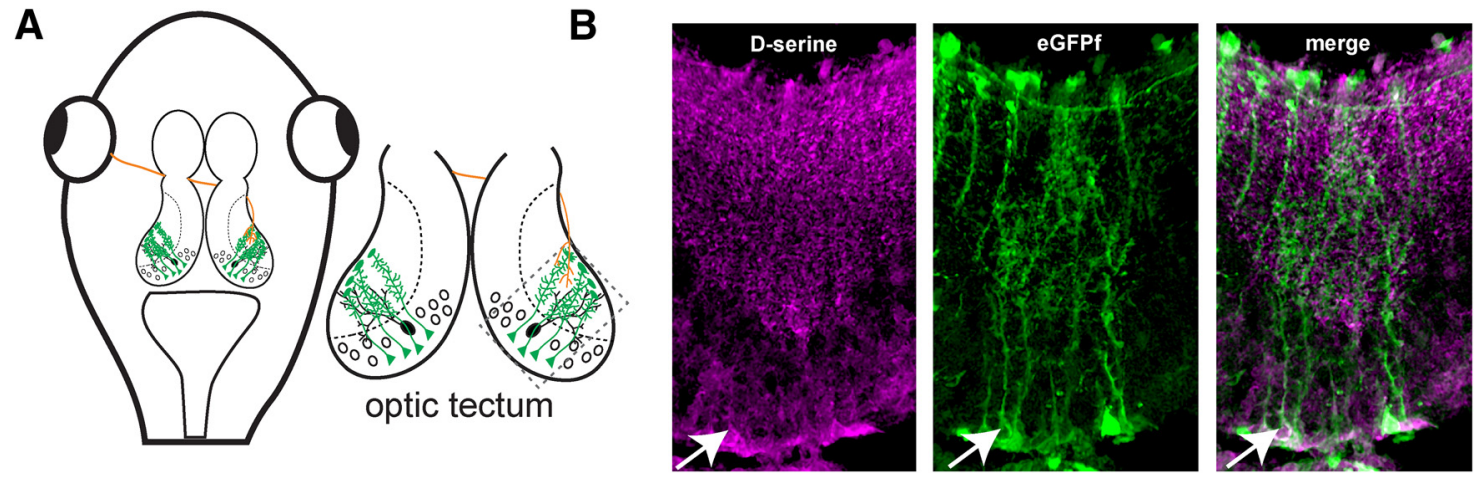

Figure 1. D-Serine is present in radial glial cells in the optic tectum. $A$, Schematic of the Xenopus tadpole optic tectum showing radial glia cells (green), RGC axons (red), and tectal neurons (black)

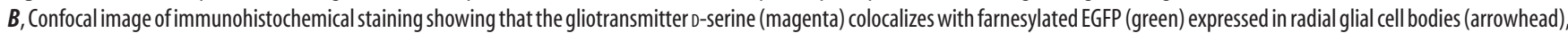
in their endfeet and in varicosities on glial fine processes throughout the tectal neuropil. Lateral is up.

were evoked by electrical stimulation of the optic nerve before and after wash-on of L-689,560, previously shown on rat cortical membranes to be a potent competitive antagonist at the NMDAR coagonist binding site (Grimwood et al., 1992). NMDAR currents were measured at $-70 \mathrm{mV}$ in $\mathrm{Mg}^{2+}$-free external, containing the AMPAR blocker NBQX. The amplitude of the NMDAR response was calculated as the peak of the current after stimulation in the presence of NBQX. Blocking the coagonist binding site with L-689,560 resulted in a complete elimination of the response (Fig. 2A,C). This finding highlights that the coagonist binding site is essential for normal NMDAR activation.

We next tested whether NMDAR responses could be modulated by changing levels of D-serine. Evoked synaptic NMDAR responses were recorded before and after D-serine application. A rapid wash-on of D-serine $(100 \mu \mathrm{M})$ was found to significantly enhance NMDAR currents (Fig. $2 B, C$ ), indicating that the coagonist binding site of the NMDAR is not saturated under basal conditions and regulation of D-serine levels could be used by the system to modulate the responses of NMDARs. Importantly, acute application of D-serine changed neither the frequency nor the amplitude of AMPAR-mediated mEPSCs recorded in the presence of TTX (Fig. 2D-F) and also had no effect on synaptically evoked PPRs (Fig. $2 G, H$ ), indicating that D-serine does not acutely facilitate release by acting directly on the presynaptic terminal.

To test whether endogenous D-serine is present and able to regulate NMDAR-mediated neurotransmission in the optic tectum, we monitored how evoked NMDAR currents were affected by the $\mathrm{D}$-amino acid degrading enzyme $\mathrm{D}$-amino acid oxidase purified from Rhodotorula gracilis (RgDAAO, $0.2 \mathrm{U} / \mathrm{ml}$ ). Exposure to $\mathrm{RgDAAO}$ for at least $15 \mathrm{~min}$ resulted in a significant reduction in the size of evoked NMDAR currents (Fig. 2I). Because DAAO generates $\mathrm{H}_{2} \mathrm{O}_{2}$ and $\mathrm{NH}_{4}$, which could be potentially cytotoxic, we examined the reversibility of inhibition by reapplying D-serine. NMDAR currents could be restored after washing out the RgDAAO with extracellular solution containing D-serine $(100 \mu \mathrm{M})$, indicating that the NMDAR was still functional (data not shown). No reduction in NMDAR currents was observed when heat-inactivated RgDAAO enzyme was used (Fig. 2I).

NMDAR-mediated EPSCs were reduced but not eliminated by RgDAAO perfusion, in agreement with previous studies which have also reported that $\mathrm{D}$-serine levels are not fully eliminated by extracellular application of the enzyme. This result is consistent with a low rate of basal D-serine release as well as the possible contribution of glycine as an additional coagonist (Panatier et al., 2006; Papouin et al., 2012).

\section{AMPAR activation results in an increase in endogenous D-serine release}

Biochemical measurements of extracellular D-serine from glial (Schell et al., 1995; Mothet et al., 2005) and neuronal cultures (Kartvelishvily et al., 2006) have shown that AMPAR stimulation can result in elevated release of D-serine. To establish whether ambient D-serine levels are modulated by glutamatergic neurotransmission in the brain, we studied its release in real time using a D-serine-sensitive enzymatic biosensor. The biosensors, which were custom designed to be small enough to insert directly into the optic tectum of the tadpole, were coated with a thin layer of DAAO on top of a perm-selectivity layer. The detection of D-serine is based on the amperometric detection of $\mathrm{H}_{2} \mathrm{O}_{2}$ produced during enzymatic degradation of D-serine by DAAO (Polcari et al., 2014) (Fig. 3A). Following calibration with known concentrations of D-serine $(0-20 \mu \mathrm{M})$ in the bath (Fig. 3B), biosensors were inserted into the tectal neuropil layer and allowed to stabilize for at least $30 \mathrm{~min}$ with PTX $(100 \mu \mathrm{M})$ and TTX $(1 \mu \mathrm{M})$ in the bath. A 10 min baseline was recorded; and then AMPA with cyclothiazide, which prevents AMPAR desensitization, was perfused into the recording chamber. We found that the addition of AMPA with cyclothiazide resulted in a rapid increase in extracellular D-serine (Fig. 3C). To ensure that the AMPA was not interacting nonspecifically with the D-serine biosensor, the experiments were repeated either in the presence of NBQX or with a null biosensor that had an identical construction but lacked the DAAO enzyme coating. Although the addition of AMPA did result in a measurable increase in current in the control conditions, it was significantly smaller than the current generated with the functionalized D-serine biosensor (Fig. 3D). The calibration curve calculated at the beginning of each experiment was used to estimate the amount of D-serine released. On average, the D-serine biosensor reported an increase in extracellular D-serine concentration of $2.65 \pm 0.66 \mu \mathrm{M}$, after the addition of AMPA and cyclothiazide.

\section{D-Serine promotes retinotectal synaptic maturation}

During development, NMDAR-dependent insertion of AMPARs is an essential aspect of the maturation of glutamatergic synapses (Wu et al., 1996). To investigate whether D-serine availability influences synapse maturation, we chronically elevated the D-serine level during a period of development when retinal ganglion axons (RGCs) are reaching the tectum and beginning to establish functional synapses (Stages 44-46). Specifically, tadpoles were raised in a rearing solution supplemented with high levels of D-serine $(100 \mu \mathrm{M})$ for $48 \mathrm{~h}$. AMPAR-mediated mEPSCs 
A

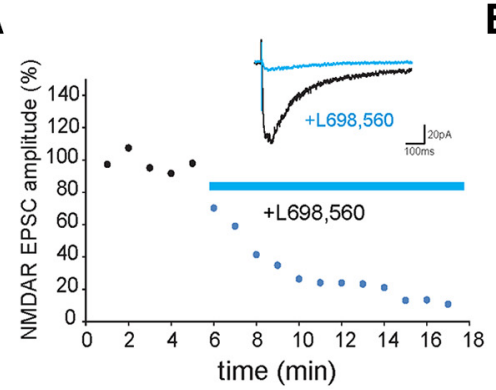

D

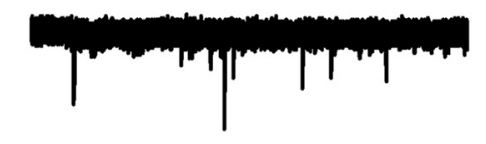

+ D-serine

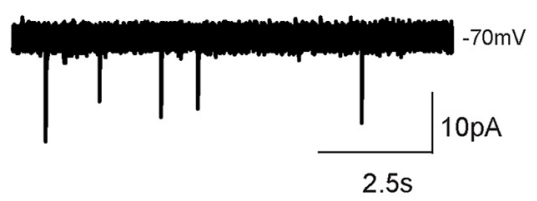

G

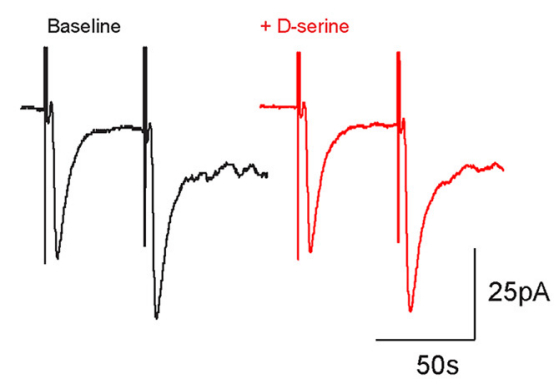

B

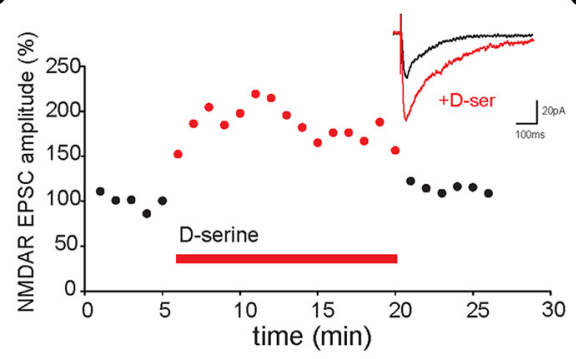

C

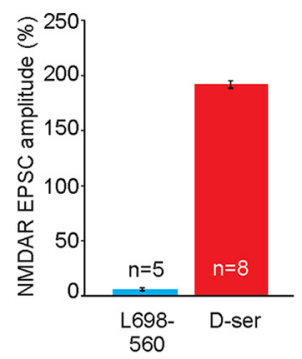

E

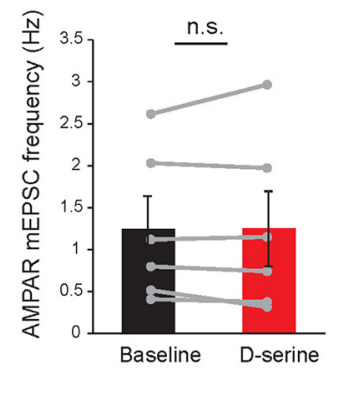

H

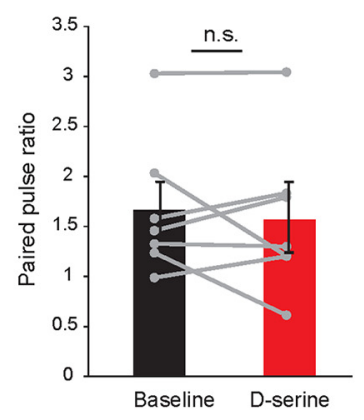

F

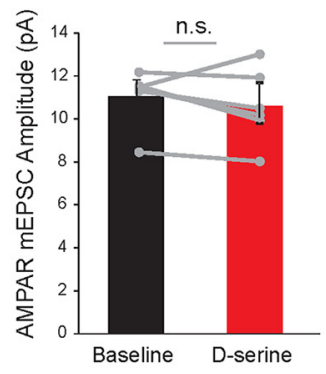

I

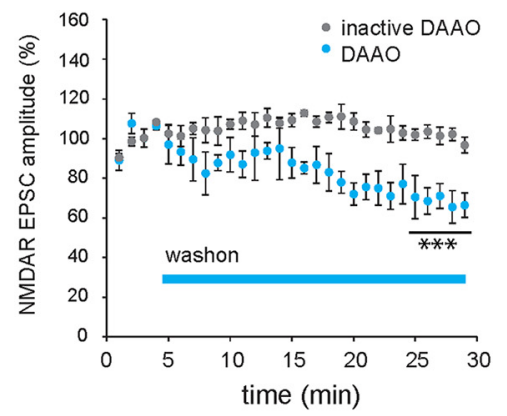

Figure 2. D-Serine is an endogenous coagonist of NMDARs at retinotectal synapses in the optic tectum. $A, B$, Example NMDAR-mediated retinotectal ESPCs recorded following optic chiasm stimulation in $0 \mathrm{~mm} \mathrm{Mg}^{2+}$, in the presence of NBQX $(20 \mu \mathrm{M})$ and PTX $(100 \mu \mathrm{m})$, from Stage 47 tadpoles (A) before (black trace) and after (blue trace) wash-on of the NMDAR coagonist site antagonist $\mathrm{L}-689,560(20 \mu \mathrm{M})$ and $(\boldsymbol{B})$ agonist D-serine (500 $\mu \mathrm{m}$, red). Insets, Averages of three trials during baseline and after 3 min of drug application. C, Mean relative changes in NMDAR-mediated EPSC amplitude measured during the last $3 \mathrm{~min}$ of drug application. $\boldsymbol{D}$, Example AMPAR-mediated mEPSC traces recorded from tectal neurons at $-70 \mathrm{mV}$ before (top) and after D-serine (bottom) application. Average mEPSC $(\boldsymbol{E})$ frequency and $(\boldsymbol{F})$ amplitude across the population of cells before and after $\mathrm{D}$-serine application are unchanged $(n=6$, frequency: $p=0.95$, amplitude: $p=0.35$, paired $t$ test). $\boldsymbol{G}$, Examples of evoked AMPAR-mediated EPSCs recorded during a $50 \mathrm{~ms} I S I$ paired pulse protocol before (black) and after D-serine (red) application. $\boldsymbol{H}$, Average PPR before and after D-serine application across the population of cells is unaltered $\left(p=0.60, n=7\right.$, paired $t$ test). $I$, Average NMDAR-mediated EPSC response decrement with RgDAA0 $\left(0.2 \mathrm{U} / \mathrm{ml}\right.$, blue, $n=5$; ${ }^{* * *} p=$ 0.00037) wash-on and NMDAR-mediated EPSCs showing lack of effect of heat-inactivated RgDAAO (gray, $n=3, p=0.70, t$ test).

were then recorded as a functional read-out of synaptic maturation. An analysis of the amplitude and frequency of the mEPSCs revealed a small shift toward larger amplitude mEPSCs and a significant increase in mEPSC frequency, compared with tadpoles raised in control rearing solution, consistent with an unsilencing of immature NMDAR-only silent synapses (Fig. 4A-E). To test specifically whether rearing animals in $\mathrm{D}$-serine drove the functional maturation of retinotectal synapses, we measured AMPA/NMDA ratios of retinotectal responses evoked by electrical stimulation of the optic tract. Animals raised in D-serine exhibited a significant increase in retinotectal synaptic AMPA/ NMDA ratios compared with control animals (Fig. $4 F, G$ ).

As the retinotectal system matures, synapses also undergo an experience-dependent increase in presynaptic probability of release (Aizenman and Cline, 2007). To test whether rearing animals in elevated D-serine promoted the maturation of presynaptic release properties, retinotectal synaptic PPRs in animals raised in D-serine were compared with PPRs in control animals over a range of ISIs. Animals chronically treated with D-serine showed significantly lower
PPR than control animals (Fig. 4H) consistent with an increase in release probability. This developmental effect is in striking contrast to the absence of any effect of acute D-serine wash-on on vesicular release (Fig. 2D-H).

To determine whether decreasing the availability of endogenous D-serine results in a deficit or slowing of normal glutamatergic maturation, RgDAAO was injected directly into the tectal ventricle from which it could gradually diffuse into the tectal neuropil. We found a significant decrease in both the amplitude and frequency of mEPSCs $24 \mathrm{~h}$ after RgDAAO injection (Fig. $5 A-C$ ), suggesting that decreasing endogenous levels of D-serine during the period of retinotectal synaptic development is sufficient to produce significant deficits in synaptic maturation.

\section{D-Serine promotes NMDAR-dependent axonal structural stabilization}

Synapse maturation is thought to promote structural stabilization of neurons in the developing visual system (Ruthazer et al., 2006). We therefore examined whether the observed D-serine- 
A

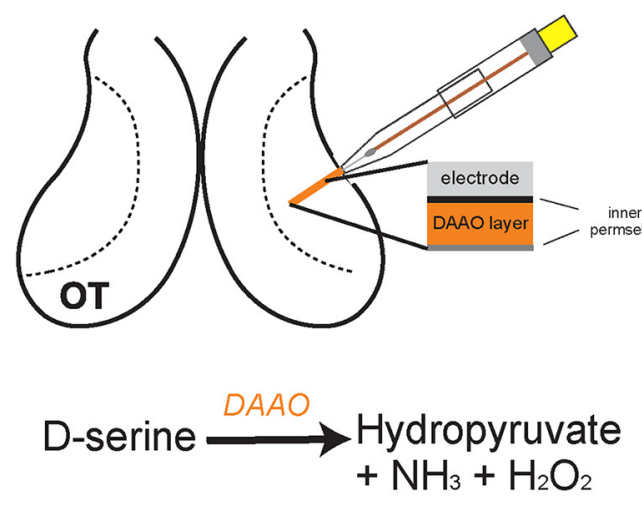

C

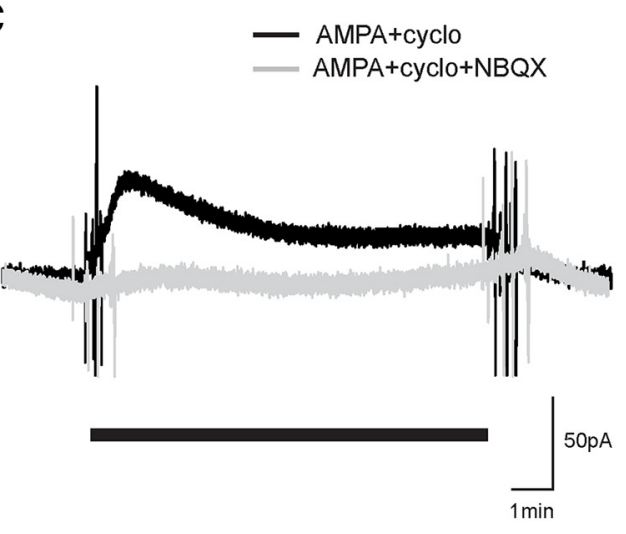

B

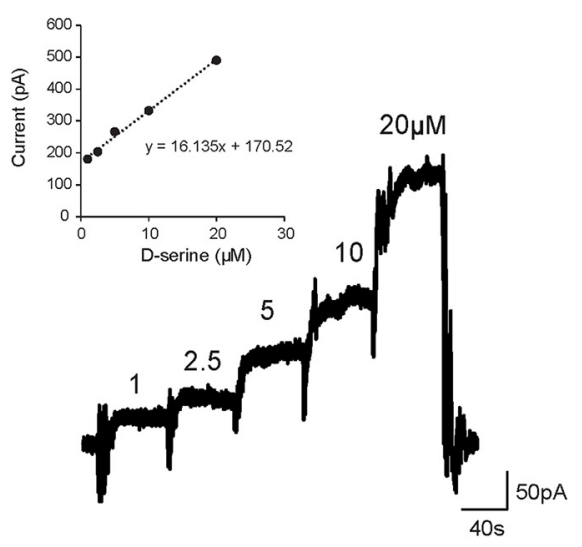

D

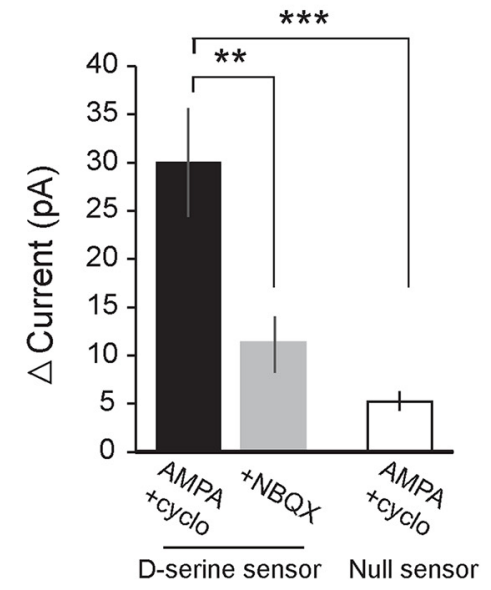

Figure 3. In situ detection of $\mathrm{D}$-serine release in the optic tectum. $A$, Schematic of the placement of the $\mathrm{D}$-serine biosensor into the neuropil of the optic tectum adjacent to the tectal cell body layer. $D$-Serine reacts with immobilized DAAO on the probe, degrading into hydroxypyruvate, ammonia, and hydrogen peroxide, which is oxidized at the biased platinum surface. $\boldsymbol{B}$, Example calibration of biosensor with standard D-serine solutions $(1,2.5,510,20 \mu \mathrm{m})$ perfused into the recording chamber. Slope of the calibration curve for each experiment was used to calculate released D-serine concentrations. C, D-Serine release was stimulated by perfusing external solution containing AMPA (100 $\mu \mathrm{M})$ with cyclothiazide $(50 \mu \mathrm{M})$ to activate AMPARs and to block receptor desensitization, respectively. $\boldsymbol{D}$, Average change in current detected by the $\mathrm{D}$-serine or control null sensor during the last $2 \mathrm{~min}$ after wash-on of AMPA and cyclothiazide (black, $\mathrm{D}$-serine sensor: $n=11$; null sensor: $n=7$ ) or AMPA, cyclothiazide, and NBQX (gray, D-serine sensor: $n=7$ ). ${ }^{* *} p=0.01$, AMPA versus AMPA + NBQX ( $t$ test). ${ }^{* * *} p=0.0015$, AMPA versus null + AMPA ( $t$ test).

mediated changes in synaptic strength were accompanied by the predicted morphological stabilization of developing RGC axons.

To visualize the effects of $\mathrm{D}$-serine on morphological development of retinotectal axons, individual RGCs were electroporated in vivo to express EGFP and live images of the axon arbor in the optic tectum were collected daily over $4 \mathrm{~d}$ to assess growth and branch elaboration. Strikingly, axonal arbors in animals reared in high levels of D-serine were found to be much less complex, with shorter total branch length and fewer branch tips, compared with control axons over $4 \mathrm{~d}$ of imaging (Fig. $6 A-C$ ). To confirm that this effect was mediated by the enhancement of NMDAR function by $\mathrm{D}$-serine, the same experiment was repeated in animals treated with the NMDAR antagonist MK-801 (10 $\mu \mathrm{M})$. Raising animals in MK-801 did not result in any significant changes in total arbor length or number of branches formed, compared with control animals (Fig. 6B, C). However, under NMDAR blockade, $D$-serine treatment no longer had the effect of reducing axonal arbor size or branch tip number (Fig. 6A-C).

These results demonstrate that, when D-serine is available at saturating concentrations, axons are driven to stabilize prematurely. To assess this more directly, axonal branch dynamic behaviors were imaged at $10 \mathrm{~min}$ intervals for $1 \mathrm{~h}$ in tadpoles that had been raised for $48 \mathrm{~h}$ in elevated D-serine. Axons in D-serinetreated animals added and lost many fewer branches compared with control axons (Fig. 7A-F). Overall, these findings support a model in which D-serine enhancement of NMDAR currents promotes synaptic maturation and leads to stabilization of axonal branches during development.

\section{Elevated levels of D-serine result in enlarged visual receptive fields}

To test the functional consequence of prolonged exposure to D-serine, we performed whole-cell recordings in vivo while presenting patterned visual stimuli through a multicore optical fiber to the contralateral eye in control animals and in animals raised in D-serine for $48 \mathrm{~h}$ (Fig. $8 A$ ). Each location in a $7 \times 7$ grid of visual subfields was illuminated at random for $1 \mathrm{~s}$ at $5 \mathrm{~s}$ intervals to map out the synaptic currents evoked by subfield illumination. Responses evoked after the illumination of the light (ON) as well as the extinction of the light (OFF) were analyzed. Representative receptive fields for $\mathrm{ON}$ and $\mathrm{OFF}$ responses are shown in Figure $8 B$ for two example cells recorded in control and D-serine animals. Consistent with previous studies, OFF responses were typically larger than corresponding $\mathrm{ON}$ responses in control animals, as indicated by the mean $\mathrm{OFF} / \mathrm{ON}$ peak response ratio of $1.74 \pm$ 0.27 (Fig. $8 C$, left). In contrast, $\mathrm{ON}$ and OFF responses from cells recorded from animals raised in D-serine were more closely matched (OFF/ON ratio: $0.83 \pm 0.08)$. Interestingly, a compari- 
A

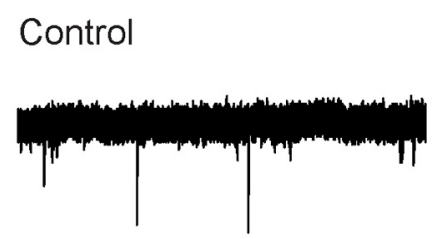

D-serine $(48 \mathrm{~h})$

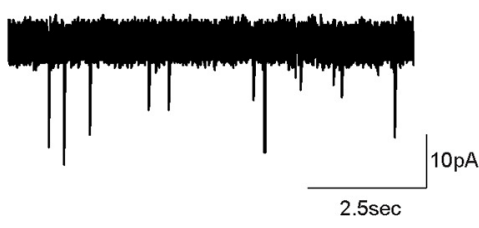

F

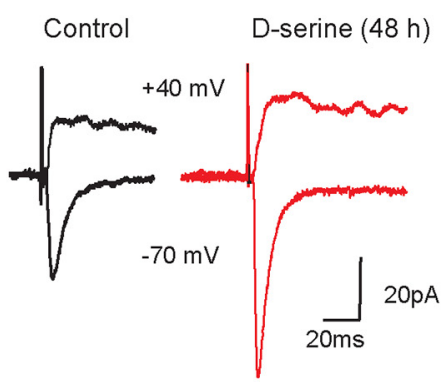

B
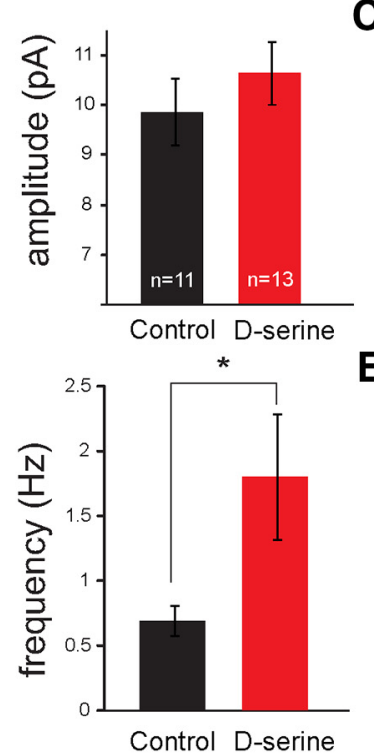

G

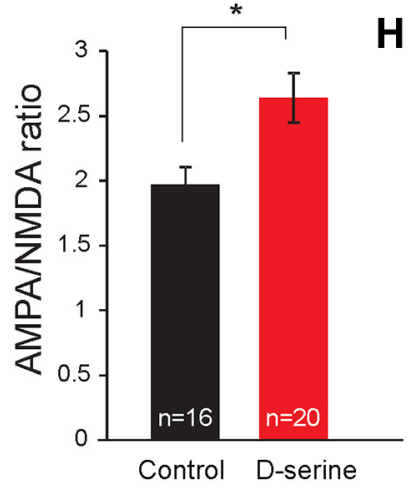

C

E

H
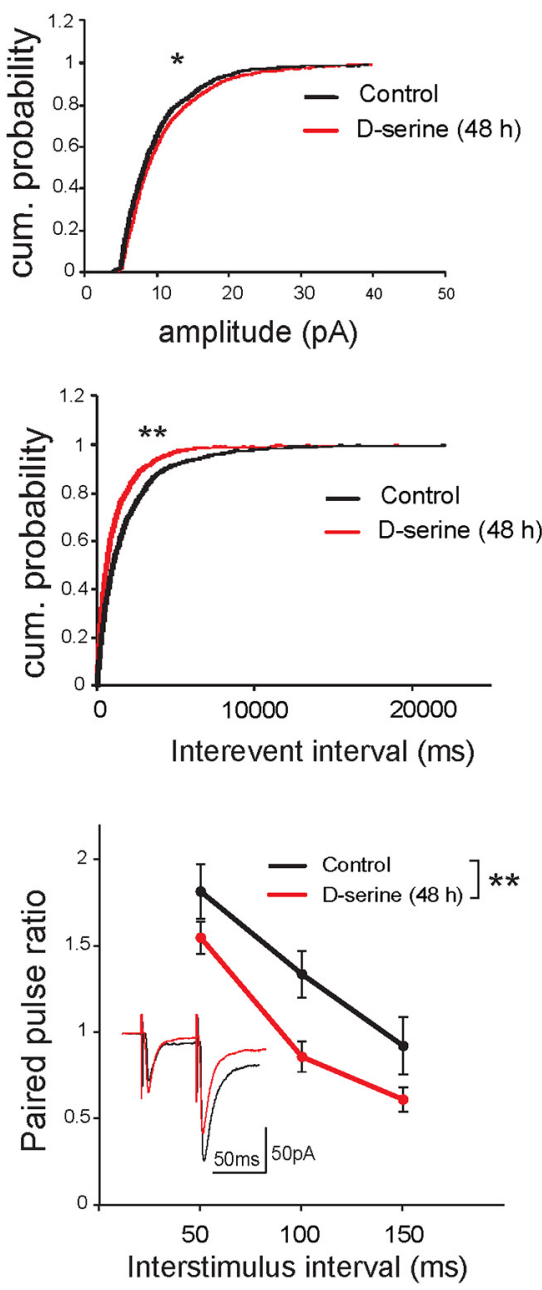

Figure 4. D-Serine promotes synaptic maturation at retinotectal synapses. $\boldsymbol{A}$, Example AMPAR-mediated mEPSC traces recorded from tectal neurons in a control animal (top) and an animal exposed to D-serine for $48 \mathrm{~h}$ (bottom). B, AMPAR-mEPSCs from neurons in control animals (black) and in animals exposed to D-serine (100 $\mu \mathrm{m}$ ) for $48 \mathrm{~h}$ (red) did not reveal a significant shift in mean amplitude ( $p=0.21$, Student's $s$ test). C, The distribution of mEPSC amplitudes (100 randomly selected events per cell) shows a modest rightward shift in the cumulative probability plot. ${ }^{*} p<0.05$ (Kolmogorov-Smirnoff test). D, AMPAR-mEPSC frequency increased dramatically in D-serine-exposed cells. ${ }^{*} p<0.05$ (Mann-Whitney test). This was also reflected in the leftward shift of (E) the interevent interval distributions. ${ }^{* *} p<0.001$ (Kolmogorov-Smirnoff test). $\boldsymbol{F}$, Example traces from tectal cell recordings of AMPAR $(-70 \mathrm{mV}$ ) and NMDAR (40 mV) responses to optic chiasm stimulation in control and D-serine-treated ( $100 \mu \mathrm{m}$ for $48 \mathrm{~h}$ ) animals. G, Average AMPA-to-NMDA ratio of retinotectal synaptic responses was increased by D-serine (100 $\mu \mathrm{m}$ for $48 \mathrm{~h}$ ) treatment. $\boldsymbol{H}$, Average PPR (EPSC2/EPSC1) across a range of ISIs for control and animals raised in D-serine for $48 \mathrm{~h} .{ }^{* *} p<0.01$ (two-way ANOVA). Inset, Example of AMPAR-mediated EPSCS recorded with a 50 $\mathrm{ms}$ ISI paired pulse protocol in control and in $48 \mathrm{~h}$ D-serine-treated (red) animals.
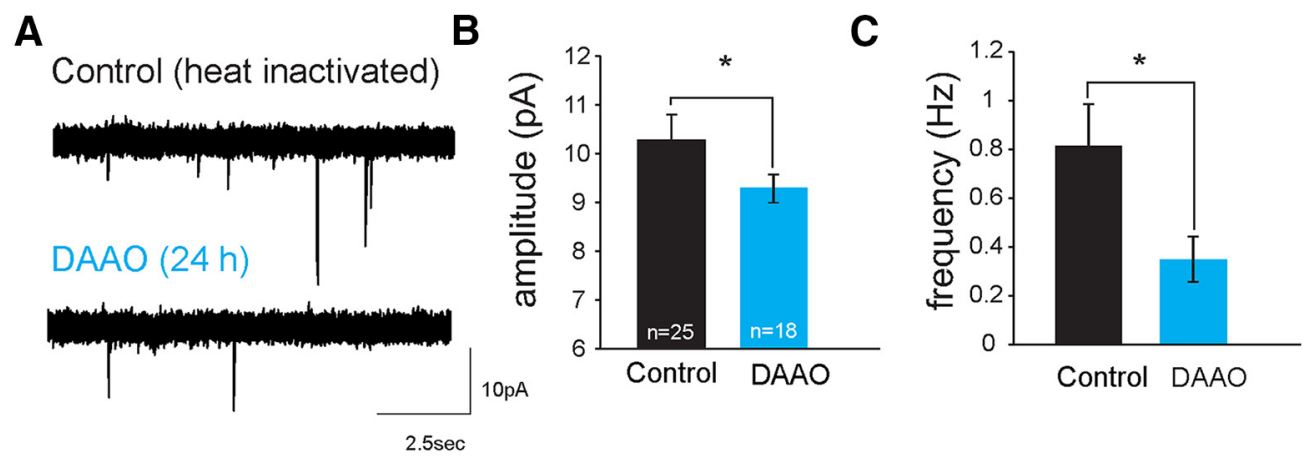

Figure 5. Reduced levels of $\mathrm{D}$-serine lead to deficits in synaptic maturation. $A$, Example AMPAR mEPSC traces recorded from neurons in a control (top) and an animal injected intraventricularly with RgDAA0 $24 \mathrm{~h}$ before recording (bottom). Average AMPAR mEPSC amplitudes $(\boldsymbol{B})$ and $(\boldsymbol{C})$ frequencies are reduced in animals treated with RgDAA0 (blue), recorded $24 \mathrm{~h}$ after RgDAA0 injection. Control animals were injected with heat-inactivated RgDAA0. ${ }^{*} p<0.05$ (Mann-Whitney test).

son of the sum of responses across all subfields revealed that the overall response is greater in D-serine animals (Fig. $8 C$, middle), and a comparison of the size of the receptive field shows that the $\mathrm{ON}$ response is significantly larger in the
D-serine animals (Fig. $8 C$, right). Together, these results suggest that $\mathrm{D}$-serine exposure promotes a nonspecific strengthening of retinal ganglion inputs leading to a more diffuse receptive field map. 

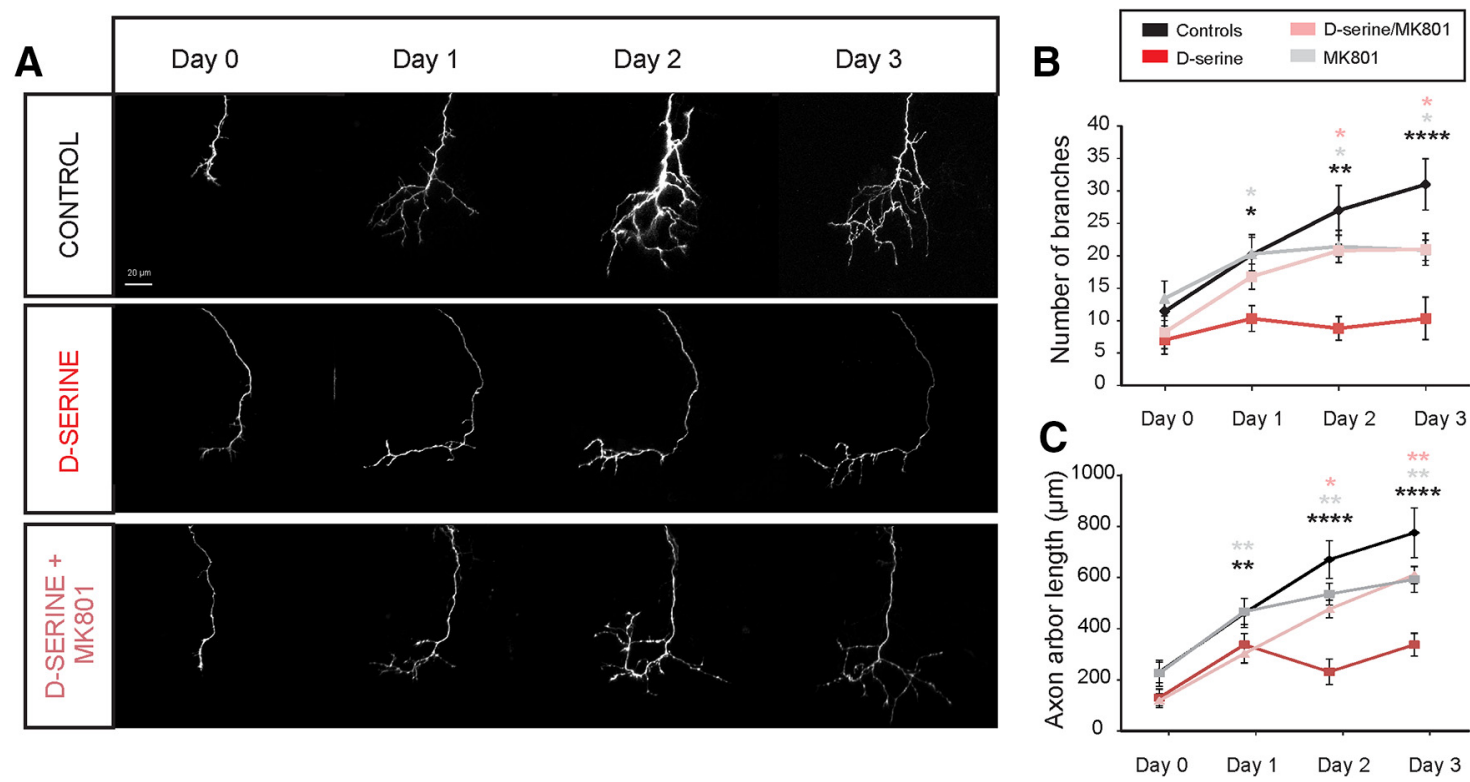

Figure 6. D-Serine results in reduced growth and branching of axonal arbors. Daily in vivo imaging of individual retinotectal axon arbors in animals electroporated to express EGFP in RGCS. Repeated imaging over $3 \mathrm{~d}$ of exposure to rearing solution containing D-serine $(100 \mu \mathrm{M})$ and/or the NMDAR antagonist MK-801 $(10 \mu \mathrm{M})$. $A$, Individual examples show greatly reduced growth and branching of D-serine-treated axons, which is rescued by NMDAR blockade. $\boldsymbol{B}$. Number of branch tips and $(\boldsymbol{C})$ total axonal arbor length for control tadpoles $(n=7)$, tadpoles raised in D-serine $(n=$ 6), MK-801 $(n=5)$, and D-serine + MK-801 $(n=7) .{ }^{*} p<0.05$, D-serine-treated versus other groups (two-way repeated-measures ANOVA with Holm-Sidak post hoc test). ${ }^{* * *} p<0.005$, D-serine-treated versus all other groups (two-way repeated-measures ANOVA with Holm-Sidak post hoc test). ${ }^{* * *} p<0.0001$, D-serine-treated versus all other groups (two-way repeatedmeasures ANOVA with Holm-Sidak post hoc test). Black asterisk versus control. Gray asterisk versus MK-801. Pink asterisk versus D-serine + MK-801.

A

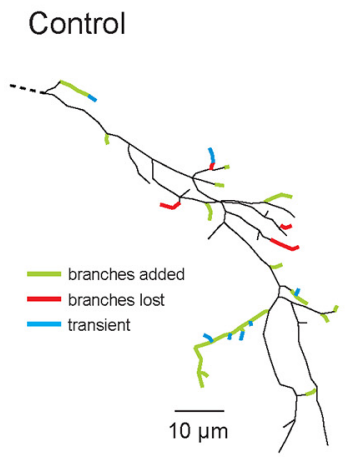

D

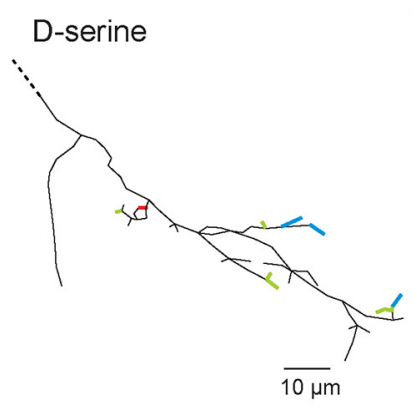

B

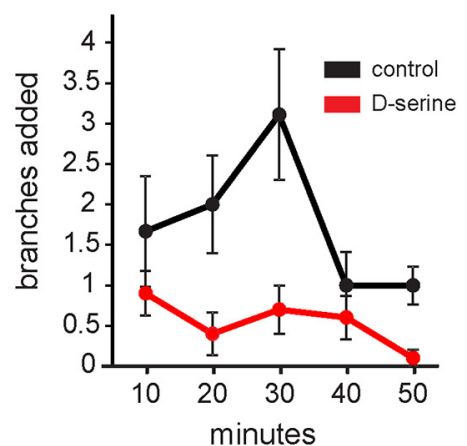

$\mathbf{E}$

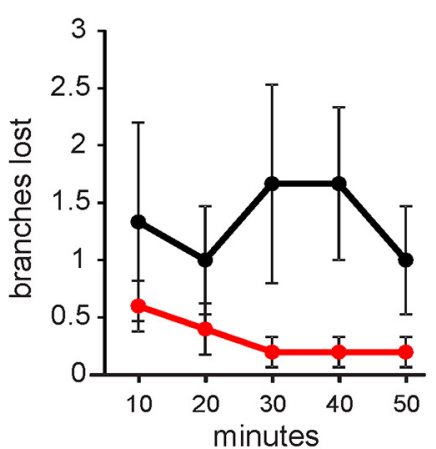

C

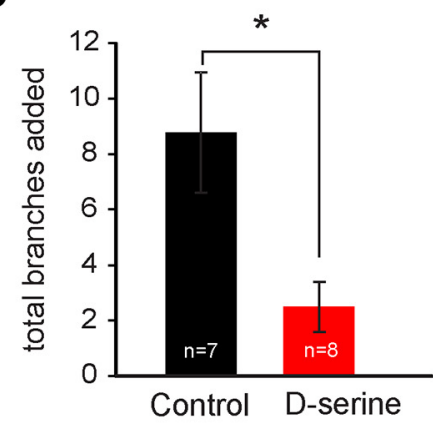

F

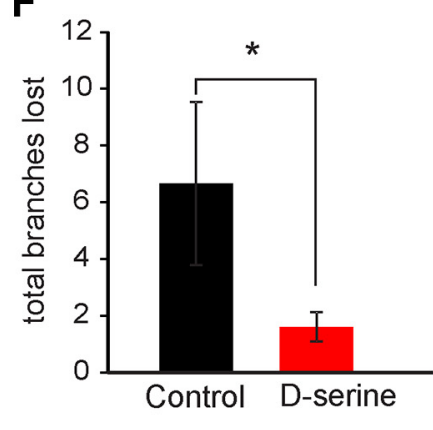

Figure 7. D-Serine results in hyperstabilization of axonal arbors. Branch dynamics measured by short-interval in vivo time-lapse imaging of RGC axonal arbors in the tectum. Example reconstructions of RGC axons imaged every $10 \mathrm{~min}$ for $1 \mathrm{~h}$ from $(\boldsymbol{A})$ a control animal and $(\boldsymbol{D})$ an animal exposed for $48 \mathrm{~h}$ to $\mathrm{D}$-serine show branches that were added ( $g r e e n)$ or lost (red). Transient branches (blue) were added and lost during the $1 \mathrm{~h}$ imaging session. The average number of branches $(\boldsymbol{B}, \boldsymbol{C})$ added and $(\boldsymbol{E}, \boldsymbol{F})$ lost every $10 \mathrm{~min}$ from control animals (black, $n=7)$ and animals exposed to $\mathrm{D}$-serine for $24-48 \mathrm{~h}$ (red, $n=8) .{ }^{*} p<0.05$ (Student's $t$ test).

\section{Discussion}

D-Serine is an endogenous coagonist of the NMDAR that is necessary for normal glutamatergic transmission. Decreasing endogenous levels of D-serine result in significant impairments in LTP in the hippocampus, hypothalamus, and visual and prefrontal cortex, suggesting that D-serine plays an important role in synaptic plasticity (Yang et al., 2003; Henneberger et al., 2010; Fossat et al., 2012; Le Bail et al., 2015; Meunier et al., 2016). Furthermore, abnormal 
A

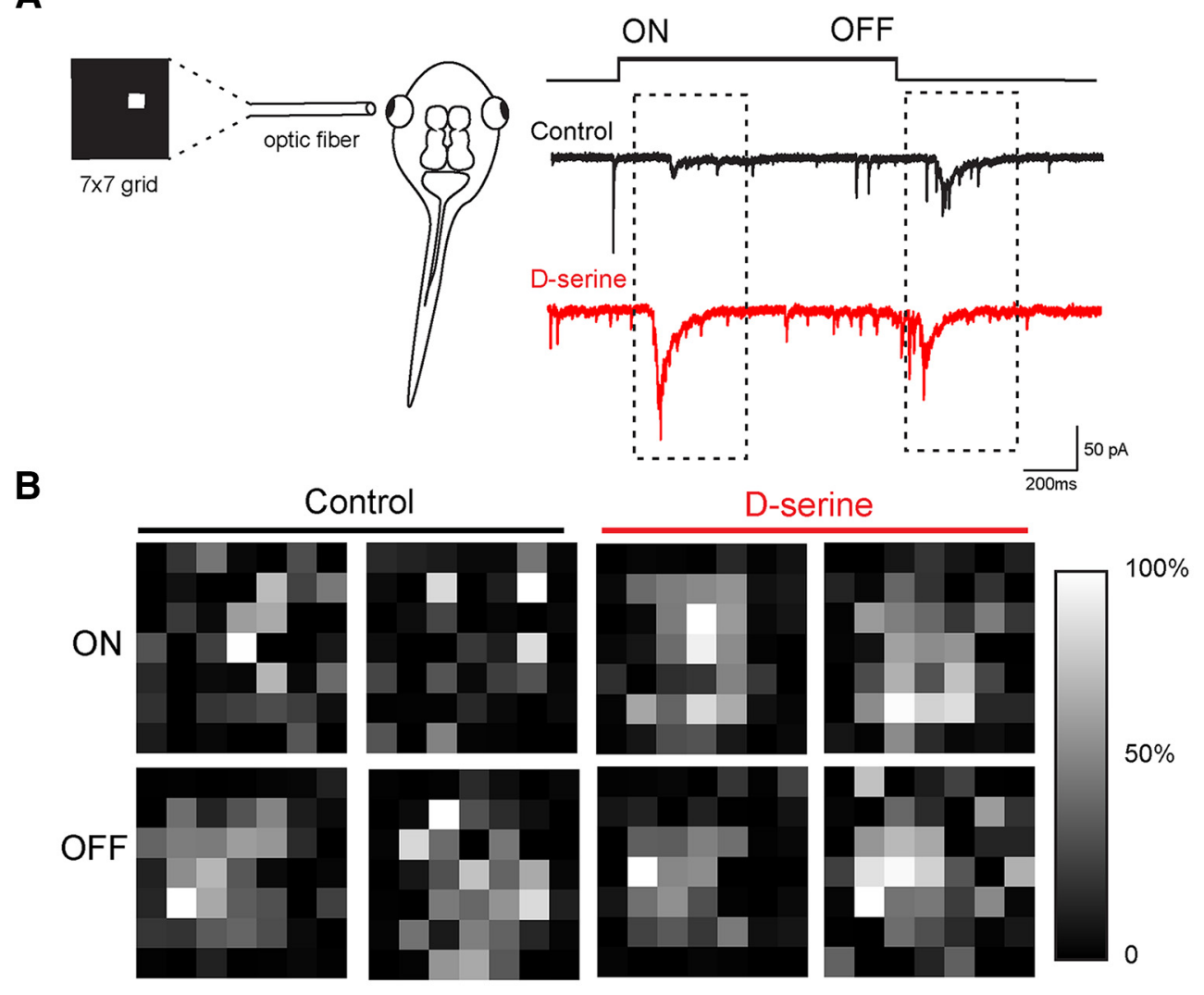

C
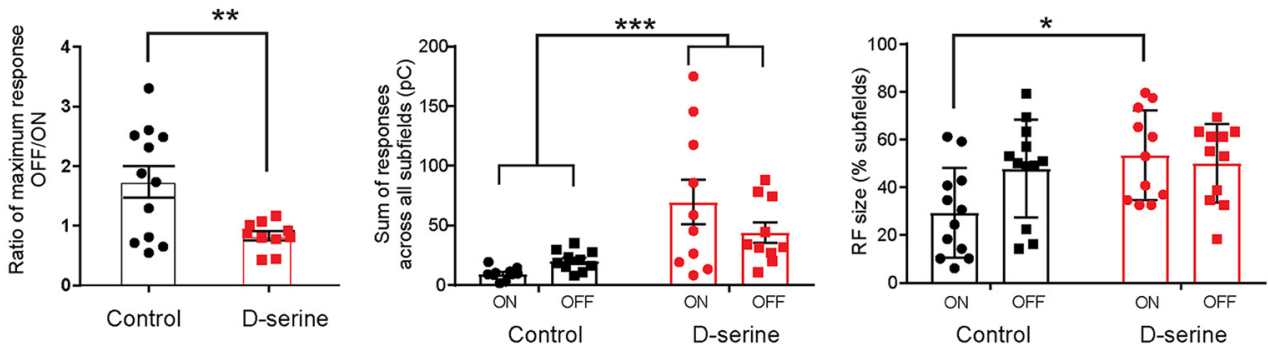

Figure 8. D-Serine increases receptive field size for $0 \mathrm{~N}$ responses. $A$, Schematic representation of the receptive field mapping setup. An optic fiber displaying a $7 \times 7$ grid of 49 individual subfields was aligned with the eye. Representative traces of whole-cell EPCSs recorded in the contralateral optic tectum in response to stimulus onset (ON) and stimulus offset (OFF) (control, black trace) (D-serine raised, red trace). $\boldsymbol{B}$, Receptive field maps for tectal neurons in two example control cells and in two cells from animals raised in D-serine. Receptive fields were generated based on synaptic responses to bright $\mathrm{ON}$ stimulation in each subfield (top) and to the stimuli turning OFF (bottom) 1 s later. Receptive fields are plotted in grayscale. White represents the strongest subfield response. C, Left, Ratios of maximum CSC generated for an OFF response to the maximum CSC for an ON response show that the relatively stronger OFF response compared with the ON response consistently seen in control cells is equalized in D-serine cells (control, $n=12$; $\mathrm{D}$-serine, $n=10$ ). ${ }^{* *} p<0.001$ ( $t$ test with one outlier removed by the ROUT outlier test). Middle, Sum of the CSCs evoked at all subfields is larger in animals raised in D-serine compared with control cells. ${ }^{* * *} p<0.001$ (two-way ANOVA, with Bonferroni post test; 3 cells removed by ROUT outlier test). Right, 0 N receptive fields are larger in animals raised in D-serine than in control animals. ${ }^{*} p<0.05$ (two-way ANOVA with Bonferroni post test).

levels of D-serine are associated with a number of neuropsychiatric and neurodegenerative disorders (Van Horn et al., 2013).

Our study reveals that proper D-serine regulation is essential for normal NMDAR-mediated synaptic transmission in the developing brain. We show that ligand binding of the NMDAR coagonist site is necessary for normal receptor activation and that increasing or decreasing endogenous levels of D-serine can, respectively, enhance or attenuate evoked NMDAR responses. We further demonstrate that D-serine levels in the developing brain are regulated by glutamatergic activation, and potentially by overall levels of neural activity.

These findings raise the intriguing question of whether activity-dependent control of D-serine release might actively regulate the development and maturation of functional retinotectal connections. During development, neurons are initially immature with so-called "silent synapses," which have NMDARs but initially lack AMPARs (Wu et al., 1996; Kerchner and Nicoll, 2008). As synapses mature, AMPARs are inserted through a process that has been shown to be dependent on the activation of NMDARs (Petralia et al., 1999).

Here we find that chronically altering levels of D-serine during a period of extensive retinotectal remodeling has a significant impact on the development of functional neural connections in vivo. Elevating levels of D-serine accelerated the normal maturation process, resulting in a higher frequency of mEPSCs events, which is consistent with an unsilencing of synapses and suggests the presence of more mature, functional synapses. Conversely, lowering D-serine levels impaired the development of synapses, manifested by a de- 
crease in mEPSC frequency and amplitude, suggesting that the circuit is left in a relatively immature state. Together, our results strongly suggest that modulation of NMDAR currents by endogenous D-serine levels may play a critical role in regulating functional synapse maturation during development. Interestingly, visual receptive fields in animals raised in D-serine are significantly larger than in control animals. Together, these data suggest that while D-serine promotes synapse maturation, through an NMDAR-dependent mechanism akin to long-term potentiation (Wu et al., 1996), this metaplastic shift in favor of functional synaptic strengthening is detrimental to the normal developmental process of visual receptive field refinement through the selective elimination of inputs.

Complimentary with these observations, a recent in vitro study showed that synaptogenesis induced by TGF- $\beta 1$ is dependent on D-serine (Diniz et al., 2012). In particular, TGF- $\beta 1$ was found to increase extracellular D-serine levels as well as promote NMDAR-dependent formation of synapses. Recently, D-serine has also been shown to be an important player in promoting the integration of adult-born neurons into the hippocampus (Sultan et al., 2015). D-Serine was found to partially restore glutamatergic synaptic transmission and spine density, which are reduced in adult-born neurons if vesicular release from local astrocytes is prevented. Along with our findings, these results indicate that D-serine plays a critical role in regulating the transition from immature to mature synapses in both developing and adult brains.

Our experiments specifically focused on the role of D-serine as an NMDAR coagonist in the development of functional neural circuits, in part because its selective action at NMDARs, as well as the specificity of RgDAAO as a tool to study endogenous D-serine, makes it a more practical target than the other wellestablished coagonist glycine. However, glycine is also present in the developing brain and is an endogenous ligand at the NMDAR coagonist binding site. Glycine is known to function as an inhibitory neurotransmitter, especially in the retina, so modulating levels of glycine during development introduces additional effects that would have complicated the interpretation of the data. There is evidence indicating that the preferred coagonist of NMDARs may be developmentally regulated and synapse specific. In the rat hippocampus, D-serine appears to be the endogenous coagonist at mature CA3-CA1 synapses, whereas glycine may be the preferred coagonist at these same synapses early in development (Papouin et al., 2012; Le Bail et al., 2015). Interestingly, changes in the preference of the coagonist from glycine to D-serine at CA3-CA1 synapses was found to closely parallel the replacement of GluN2B- by GluN2A-containing NMDARs. Moreover, D-serine was found to delay the insertion of GluN2BNMDARs, whereas glycine was found to impede the insertion of GluN2A-NMDAR subunits at the synapse, suggesting a potential role of the coagonist in determining which receptor types are trafficked to synapses (Papouin et al., 2012). In the Xenopus optic tectum, concurrent expression of both GluN2A and GluN2B subunits at the developmental stages we studied suggests that both glycine and D-serine may serve as coagonists for NMDARs at these points in development (Cline et al., 1996; Aizenman and Cline, 2007; Ewald et al., 2008). Complementary experiments to our $R g \mathrm{DAAO}$ treatment, using the glycine-degrading enzyme glycine oxidase, could be carefully incorporated into future studies to determine the relative contributions of each coagonist.

The maturation of excitatory synaptic inputs is paralleled by distinct structural changes in neurons. In particular, synapse maturation has been shown to participate in the stabilization of axonal (Alsina et al., 2001; Ruthazer et al., 2006) and dendritic arbors (Niell et al., 2004; Haas et al., 2006). The NMDAR is a critical player in the maturation of neural circuits. Blocking or genetically disrupting NMDARs interferes with normal activitydependent topographic map development (Constantine-Paton et al., 1990; Ruthazer and Cline, 2004; Dong et al., 2009; Erzurumlu and Gaspar, 2012). In live imaging experiments, NMDAR blockade has been shown to increase axonal branch dynamics in RGCs, consistent with a role in axon branch stabilization (Rajan et al., 1999; Munz et al., 2014). Interestingly, blockade of NMDARs may not translate to an increase in RGC axonal arbor size or branchtip number. In the present study, we found that axons in animals raised in MK-801 were not significantly different from control axons. Moreover, Rajan et al. (1999) reported no net change in axon size after $24 \mathrm{~h}$ of APV treatment despite an increase in overall branch dynamics. This is surprising considering our imaging experiments show that D-serine exposure leads to arbor stabilization, resulting in smaller arbors over days. However, because these data are all based on single-cell reconstructions, it is not possible to conclude that the precise locations of arbor termination zones are unaffected. For example, NMDAR blockade may result in a disruption of the process of axon input convergence and pruning that contributes to topographic map refinement. Consistent with this, a previous examination of receptive field properties in animals raised in MK-801 showed that NMDAR blockade results in broader receptive fields compared with controls (Dong et al., 2009). Interestingly, we find that D-serine exposure also results in enlarged receptive field sizes compared with controls. Together, these experiments support the notion that a critical role for NMDAR-dependent neuroplasticity during development is to promote the convergence of coactive inputs (Kutsarova et al., 2017). Proper input convergence may lose specificity as a consequence either of insufficient or of indiscriminate NMDAR activation.

Early studies attempted to test the effects of enhanced NMDAR activation on axon remodeling by chronically applying NMDA, but these were likely confounded by receptor desensitization leading to synaptic silencing (O'Rourke et al., 1994). The experiments presented here exploit D-serine as an allosteric NMDAR activator that enhances physiological glutamatergic activation. They provide the first demonstration based on gain-of-function data that NMDAR signaling contributes to stabilizing axons in the developing visual system.

Determining the functional source of D-serine remains a topic of extensive investigation (Ehmsen et al., 2013; Martineau et al., 2013; Radzishevsky et al., 2013; Rosenberg et al., 2013; Balu et al., 2014; Martineau et al., 2014). Accumulating evidence suggests both neuronal and glial sources of $\mathrm{D}$-serine synthesis, but recent studies point to different mechanisms of release. In astrocytes, evidence of calcium-dependent vesicular D-serine release has been reported in the hippocampus (Henneberger et al., 2010; Martineau et al., 2014) and calcium-independent D-serine release via pannexin-1 hemichannels has been reported in astrocyte cultures (Pan et al., 2015). In contrast, amino acid transporters have been implicated in neuronal D-serine release (Rosenberg et al., 2013).

Our immunostaining shows that radial glia cells in the developing Xenopus optic tectum contain significant amounts of D-serine. Using enzymatic biosensors in the brain, we show that glutamatergic activation of AMPARs leads to a rapid and substantial increase in D-serine levels. These results support the general model that D-serine is a gliotransmitter, and suggest that the D-serine release is mediated, at least in part, through glutamatergic activation. Previous studies from our laboratory have shown 
that visual stimulation results in increased calcium transients in radial glia cells (Tremblay et al., 2009) and that manipulations that block glial structural dynamics prevent normal synaptic maturation (Sild et al., 2016). Overall, our results are consistent with a model in which neuronal glutamate release activates AMPARs located on neighboring glial cells, triggering the release of D-serine, which could act back on nearby synapses to promote their stabilization. Determining whether D-serine is primarily released from glia or neurons in the developing visual system will be an important goal for future study.

Imbalances in D-serine levels have been associated with a number of CNS disorders, including schizophrenia, depression, Alzheimer's disease, and amyotrophic lateral sclerosis (Sasabe et al., 2007; Van Horn et al., 2013; Paul and de Belleroche, 2014; Balu and Coyle, 2015). Measurements of D-serine levels in postmortem tissue and CSF show that schizophrenic patients have lower levels of D-serine and associated D-serine enzymes (Bendikov et al., 2007) and Alzheimer patients had higher levels of D-serine (Madeira et al., 2015). Genetic studies have also implicated a number of genes in schizophrenic and Alzheimer patients that are associated with the regulation of D-serine (Goltsov et al., 2006; Morita et al., 2007).

Notably, recent evidence suggests that developmental dysregulation of D-serine may significantly contribute to the etiology of certain psychiatric diseases. Early genetic disruption of D-serine synthesis in mice leads to decreases in $\mathrm{D}$-serine levels and behavioral abnormalities associated with schizophrenia in adulthood (Hagiwara et al., 2013; Nomura et al., 2016). Interestingly, behavioral deficits are rescued in these mice if D-serine is given early in development but not if given in adulthood, suggesting that regulation of D-serine early in development may be instrumental in setting up the proper network connections for functional behavior later in life. High-dose D-serine administration has already begun to emerge in the clinics as a promising potential treatment for the negative symptoms of schizophrenia (Hashimoto, 2014), and D-serine is currently under investigation as a potential biomarker for early detection of Alzheimer's disease (Madeira et al., 2015). Understanding D-serine's potential roles and benefits in brain development will likely be essential for establishing effective preventative therapies.

\section{References}

Aizenman CD, Cline HT (2007) Enhanced visual activity in vivo forms nascent synapses in the developing retinotectal projection. J Neurophysiol 97:2949-2957. CrossRef Medline

Alsina B, Vu T, Cohen-Cory S (2001) Visualizing synapse formation in arborizing optic axons in vivo: dynamics and modulation by BDNF. Nat Neurosci 4:1093-1101. CrossRef Medline

Assali A, Gaspar P, Rebsam A (2014) Activity dependent mechanisms of visual map formation-from retinal waves to molecular regulators. Semin Cell Dev Biol 35:136-146. CrossRef Medline

Balu DT, Coyle JT (2015) The NMDA receptor 'glycine modulatory site' in schizophrenia: D-serine, glycine, and beyond. Curr Opin Pharmacol 20: 109-115. CrossRef Medline

Balu DT, Takagi S, Puhl MD, Benneyworth MA, Coyle JT (2014) D-Serine and serine racemase are localized to neurons in the adult mouse and human forebrain. Cell Mol Neurobiol 34:419-435. CrossRef Medline

Bendikov I, Nadri C, Amar S, Panizzutti R, De Miranda J, Wolosker H, Agam G (2007) A CSF and postmortem brain study of D-serine metabolic parameters in schizophrenia. Schizophr Res 90:41-51. CrossRef Medline

Cline HT, Debski EA, Constantine-Paton M (1987) N-methyl-D-aspartate receptor antagonist desegregates eye-specific stripes. Proc Natl Acad Sci U S A 84:4342-4345. CrossRef Medline

Cline HT, Wu GY, Malinow R (1996) In vivo development of neuronal structure and function. Cold Spring Harb Symp Quant Biol 61:95-104. CrossRef Medline

Constantine-Paton M, Cline HT, Debski E (1990) Patterned activity, synaptic convergence, and the NMDA receptor in developing visual pathways. Annu Rev Neurosci 13:129-154. CrossRef Medline
Danysz W, Parsons CG (1998) Glycine and N-methyl-D-aspartate receptors: physiological significance and possible therapeutic applications. Pharmacol Rev 50:597-664. Medline

Diniz LP, Almeida JC, Tortelli V, Vargas Lopes C, Setti-Perdigão P, Stipursky J, Kahn SA, Romão LF, de Miranda J, Alves-Leon SV, de Souza JM, Castro NG, Panizzutti R, Gomes FC (2012) Astrocyte-induced synaptogenesis is mediated by transforming growth factor beta signaling through modulation of D-serine levels in cerebral cortex neurons. J Biol Chem 287: 41432-41445. CrossRef Medline

Dong W, Lee RH, Xu H, Yang S, Pratt KG, Cao V, Song YK, Nurmikko A, Aizenman CD (2009) Visual avoidance in Xenopus tadpoles is correlated with the maturation of visual responses in the optic tectum. J Neurophysiol 101:803-815. Medline

Ehmsen JT, Ma TM, Sason H, Rosenberg D, Ogo T, Furuya S, Snyder SH, Wolosker $\mathrm{H}$ (2013) D-Serine in glia and neurons derives from 3-phosphoglycerate dehydrogenase. J Neurosci 33:12464-12469. CrossRef Medline

Erzurumlu RS, Gaspar P (2012) Development and critical period plasticity of the barrel cortex. Eur J Neurosci 35:1540-1553. CrossRef Medline

Ewald RC, Van Keuren-Jensen KR, Aizenman CD, Cline HT (2008) Roles of NR2A and NR2B in the development of dendritic arbor morphology in vivo. J Neurosci 28:850-861. CrossRef Medline

Feldman DE, Brainard MS, Knudsen EI (1996) Newly learned auditory responses mediated by NMDA receptors in the owl inferior colliculus. Science 271:525-528. CrossRef Medline

Fossat P, Turpin FR, Sacchi S, Dulong J, Shi T, Rivet JM, Sweedler JV, Pollegioni L, Millan MJ, Oliet SH, Mothet JP (2012) Glial D-serine gates NMDA receptors at excitatory synapses in prefrontal cortex. Cereb Cortex 22:595-606. CrossRef Medline

Goltsov AY, Loseva JG, Andreeva TV, Grigorenko AP, Abramova LI, Kaleda VG, Orlova VA, Moliaka YK, Rogaev EI (2006) Polymorphism in the 5 '-promoter region of serine racemase gene in schizophrenia. Mol Psychiatry 11:325-326. CrossRef Medline

Grimwood S, Moseley AM, Carling RW, Leeson PD, Foster AC (1992) Characterization of the binding of $\left[{ }^{3} \mathrm{H}\right] \mathrm{L}-689,560$, an antagonist for the glycine site on the N-methyl-D-aspartate receptor, to rat brain membranes. Mol Pharmacol 41:923-930. Medline

Haas K, Li J, Cline HT (2006) AMPA receptors regulate experiencedependent dendritic arbor growth in vivo. Proc Natl Acad Sci U S A 103: 12127-12131. CrossRef Medline

Hagiwara H, Iyo M, Hashimoto K (2013) Neonatal disruption of serine racemase causes schizophrenia-like behavioral abnormalities in adulthood: clinical rescue by d-serine. PLoS One 8:e62438. CrossRef Medline

Hashimoto A, Nishikawa T, Oka T, Takahashi K (1993) Endogenous D-serine in rat brain: $\mathrm{N}$-methyl-D-aspartate receptor-related distribution and aging. J Neurochem 60:783-786. CrossRef Medline

Hashimoto K (2014) Targeting of NMDA receptors in new treatments for schizophrenia. Expert Opin Ther Targets 18:1049-1063. CrossRef Medline

Henneberger C, Papouin T, Oliet SH, Rusakov DA (2010) Long-term potentiation depends on release of D-serine from astrocytes. Nature 463: 232-236. CrossRef Medline

Hossain S, Hewapathirane DS, Haas K (2012) Dynamic morphometrics reveals contributions of dendritic growth cones and filopodia to dendritogenesis in the intact and awake embryonic brain. Dev Neurobiol 72: 615-627. CrossRef Medline

Johnson JW, Ascher P (1987) Glycine potentiates the NMDA response in cultured mouse brain neurons. Nature 325:529-531. CrossRef Medline

Kartvelishvily E, Shleper M, Balan L, Dumin E, Wolosker H (2006) Neuronderived D-serine release provides a novel means to activate N-methyl-Daspartate receptors. J Biol Chem 281:14151-14162. CrossRef Medline

Kerchner GA, Nicoll RA (2008) Silent synapses and the emergence of a postsynaptic mechanism for LTP. Nat Rev Neurosci 9:813-825. CrossRef Medline

Kutsarova E, Munz M, Ruthazer ES (2017) Rules for shaping neural connections in the developing brain. Front Neural Circuits 10:111. Medline

Le Bail M, Martineau M, Sacchi S, Yatsenko N, Radzishevsky I, Conrod S, Ait Ouares K, Wolosker H, Pollegioni L, Billard JM, Mothet JP (2015) Identity of the NMDA receptor coagonist is synapse specific and developmentally regulated in the hippocampus. Proc Natl Acad Sci U S A 112:E204-E213. CrossRef Medline

Madeira C, Lourenco MV, Vargas-Lopes C, Suemoto CK, Brandão CO, Reis T, Leite RE, Laks J, Jacob-Filho W, Pasqualucci CA, Grinberg LT, Ferreira ST, Panizzutti R (2015) D-Serine levels in Alzheimer's disease: implica- 
tions for novel biomarker development. Transl Psychiatry 5:e561. CrossRef Medline

Martineau M, Shi T, Puyal J, Knolhoff AM, Dulong J, Gasnier B, Klingauf J, Sweedler JV, Jahn R, Mothet JP (2013) Storage and uptake of D-serine into astrocytic synaptic-like vesicles specify gliotransmission. J Neurosci 33:3413-3423. CrossRef Medline

Martineau M, Parpura V, Mothet JP (2014) Cell-type specific mechanisms of D-serine uptake and release in the brain. Front Synaptic Neurosci 6:12. CrossRef Medline

Meunier CN, Dallérac G, Le Roux N, Sacchi S, Levasseur G, Amar M, Pollegioni L, Mothet JP, Fossier P (2016) D-Serine and glycine differentially control neurotransmission during visual cortex critical period. PLoS One 11:e0151233. CrossRef Medline

Molla G, Vegezzi C, Pilone MS, Pollegioni (1998) Overexpression in Escherichia coli of an recombinant chimeric Rhodotorula gracilis $\mathrm{D}$-amino acid oxidase. Prot Express Purif 14:289-294.

Morita Y, Ujike H, Tanaka Y, Otani K, Kishimoto M, Morio A, Kotaka T, Okahisa Y, Matsushita M, Morikawa A, Hamase K, Zaitsu K, Kuroda S (2007) A genetic variant of the serine racemase gene is associated with schizophrenia. Biol Psychiatry 61:1200-1203. CrossRef Medline

Mothet JP, Pollegioni L, Ouanounou G, Martineau M, Fossier P, Baux G (2005) Glutamate receptor activation triggers a calcium-dependent and SNARE protein-dependent release of the gliotransmitter D-serine. Proc Natl Acad Sci U S A 102:5606-5611. CrossRef Medline

Mothet JP, Le Bail M, Billard JM (2015) Time and space profiling of NMDA receptor co-agonist functions. J Neurochem 135:210-225. CrossRef Medline

Munz M, Gobert D, Schohl A, Poquérusse J, Podgorski K, Spratt P, Ruthazer ES (2014) Rapid Hebbian axonal remodeling mediated by visual stimulation. Science 344:904-909. CrossRef Medline

Niell CM, Meyer MP, Smith SJ (2004) In vivo imaging of synapse formation on a growing dendritic arbor. Nat Neurosci 7:254-260. CrossRef Medline

Nomura J, Jaaro-Peled H, Lewis E, Nuñez-Abades P, Huppe-Gourgues F, Cash-Padgett T, Emiliani F, Kondo MA, Furuya A, Landek-Salgado MA, Ayhan Y, Kamiya A, Takumi T, Huganir R, Pletnikov M, O’Donnell P, Sawa A (2016) Role for neonatal D-serine signaling: prevention of physiological and behavioral deficits in adult Pick1 knockout mice. Mol Psychiatry 21:386-393. CrossRef Medline

O'Rourke NA, Cline HT, Fraser SE (1994) Rapid remodeling of retinal arbors in the tectum with and without blockade of synaptic transmission. Neuron 12:921-934. CrossRef Medline

Pan HC, Chou YC, Sun SH (2015) P2X7 R-mediated Ca(2+)-independent D-serine release via pannexin-1 of the P2X7 R-pannexin-1 complex in astrocytes. Glia 63:877-893. CrossRef Medline

Panatier A, Theodosis DT, Mothet JP, Touquet B, Pollegioni L, Poulain DA, Oliet SH (2006) Glia-derived D-serine controls NMDA receptor activity and synaptic memory. Cell 125:775-784. CrossRef Medline

Papouin T, Ladépêche L, Ruel J, Sacchi S, Labasque M, Hanini M, Groc L, Pollegioni L, Mothet JP, Oliet SH (2012) Synaptic and extrasynaptic NMDA receptors are gated by different endogenous coagonists. Cell 150: 633-646. CrossRef Medline

Paul P, de Belleroche J (2014) The role of D-serine and glycine as co-agonists of NMDA receptors in motor neuron degeneration and amyotrophic lateral sclerosis (ALS). Front Synaptic Neurosci 6:10. CrossRef Medline

Petralia RS, Esteban JA, Wang YX, Partridge JG, Zhao HM, Wenthold RJ, Malinow R (1999) Selective acquisition of AMPA receptors over post- natal development suggests a molecular basis for silent synapses. Nat Neurosci 2:31-36. CrossRef Medline

Polcari D, Kwan A, Van Horn MR, Danis L, Pollegioni L, Ruthazer ES, Mauzeroll J (2014) Disk-shaped amperometric enzymatic biosensor for in vivo detection of D-serine. Anal Chem 86:3501-3507. CrossRef Medline

Radzishevsky I, Sason H, Wolosker H (2013) D-serine: physiology and pathology. Curr Opin Clin Nutr Metab Care 16:72-75. CrossRef Medline

Rajan I, Witte S, Cline HT (1999) NMDA receptor activity stabilizes presynaptic retinotectal axons and postsynaptic optic tectal cell dendrites in vivo. J Neurobiol 38:357-368. CrossRef Medline

Rosenberg D, Artoul S, Segal AC, Kolodney G, Radzishevsky I, Dikopoltsev E, Foltyn VN, Inoue R, Mori H, Billard JM, Wolosker H (2013) Neuronal D-serine and glycine release via the Asc-1 transporter regulates NMDA receptor-dependent synaptic activity. J Neurosci 33:3533-3544. CrossRef Medline

Ruthazer ES, Cline HT (2004) Insights into activity-dependent map formation from the retinotectal system: a middle-of-the-brain perspective. J Neurobiol 59:134-146. CrossRef Medline

Ruthazer ES, Akerman CJ, Cline HT (2003) Control of axon branch dynamics by correlated activity in vivo. Science 301:66-70. CrossRef Medline

Ruthazer ES, Li J, Cline HT (2006) Stabilization of axon branch dynamics by synaptic maturation. J Neurosci 26:3594-3603. CrossRef Medline

Ruthazer ES, Schohl A, Schwartz N, Tavakoli A, Tremblay M, Cline HT (2013) Bulk electroporation of retinal ganglion cells in live Xenopus tadpoles. Cold Spring Harb Protoc 2013:771-775. CrossRef Medline

Sasabe J, Chiba T, Yamada M, Okamoto K, Nishimoto I, Matsuoka M, Aiso S (2007) D-Serine is a key determinant of glutamate toxicity in amyotrophic lateral sclerosis. EMBO J 26:4149-4159. CrossRef Medline

Schell MJ, Molliver ME, Snyder SH (1995) D-Serine, an endogenous synaptic modulator: localization to astrocytes and glutamate-stimulated release. Proc Natl Acad Sci U S A 92:3948-3952. CrossRef Medline

Sild M, Van Horn MR, Schohl A, Jia D, Ruthazer ES (2016) Neural activitydependent regulation of radial glial filopodial motility is mediated by glial cGMP-dependent protein kinase 1 and contributes to synapse maturation in the developing visual system. J Neurosci 36:5279-5288. CrossRef Medline

Simon DK, Prusky GT, O'Leary DD, Constantine-Paton M (1992) N-methylD-aspartate receptor antagonists disrupt the formation of a mammalian neural map. Proc Natl Acad Sci U S A 89:10593-10597. CrossRef Medline

Sultan S, Li L, Moss J, Petrelli F, Cassé F, Gebara E, Lopatar J, Pfrieger FW, Bezzi P, Bischofberger J, Toni N (2015) Synaptic integration of adultborn hippocampal neurons is locally controlled by astrocytes. Neuron 88:957-972. CrossRef Medline

Tremblay M, Fugère V, Tsui J, Schohl A, Tavakoli A, Travençolo BA, Costa Lda F, Ruthazer ES (2009) Regulation of radial glial motility by visual experience. J Neurosci 29:14066-14076. CrossRef Medline

Van Horn MR, Sild M, Ruthazer ES (2013) D-Serine as a gliotransmitter and its roles in brain development and disease. Front Cell Neurosci 7:39. CrossRef Medline

Wolosker H (2007) NMDA receptor regulation by D-serine: new findings and perspectives. Mol Neurobiol 36:152-164. CrossRef Medline

Wu G, Malinow R, Cline HT (1996) Maturation of a central glutamatergic synapse. Science 274:972-976. CrossRef Medline

Yang Y, Ge W, Chen Y, Zhang Z, Shen W, Wu C, Poo M, Duan S (2003) Contribution of astrocytes to hippocampal long-term potentiation through release of D-serine. Proc Natl Acad Sci U S A 100:15194-15199. CrossRef Medline 